\title{
Antigenotoxic effect of green-synthesised silver nanoparticles from Ocimum sanctum leaf extract against cyclophosphamide induced genotoxicity in human lymphocytes-in vitro
}

\author{
P. P. Vijaya $\cdot$ B. Rekha $\cdot$ Anu Thersa Mathew $\cdot$ \\ M. Syed Ali $\cdot$ N. Yogananth $\cdot$ V. Anuradha • \\ P. Kalitha Parveen
}

Received: 19 January 2013/ Accepted: 13 March 2013/Published online: 10 April 2013

(c) The Author(s) 2013. This article is published with open access at Springerlink.com

\begin{abstract}
The present study was aimed to identify the antigenotoxic effect of bio-synthesised silver nanoparticles (SNP) of Ocimum sanctum leaf extract against cyclophosphamide (CP). We tested the antigenotoxic effect of bio-synthesized silver nanoparticles of $O$. sanctum leaf extract on human lymphocytes against $\mathrm{CP}$ by using chromosomal aberration assay (CAA). Silver nanoparticles was first synthesized from fresh leaf extract of $O$. sanctum and characterised. Their quality was checked by XRD technique and morphology by SEM. Three different doses of the bio-synthesised SNPs namely, 50, 100 and $200 \mu \mathrm{l} / \mathrm{ml}$ were selected and CP $(100 \mu \mathrm{g} / \mathrm{ml})$ was used as a positive control for CAA. CP administration to human lymphocytes culture caused reduction in mitotic index (MI) and increase in chromosomal damages. The three doses $(50,100$ and $200 \mu \mathrm{l} / \mathrm{ml})$ significantly $(P<0.005)$ reduced the chromosomal damages by $\mathrm{CP}$ and there was increase in MI. The biological way of synthesising SNPs has advantages like cost effectiveness and eco-friendly. Also the bio-synthesised SNPs of $O$. sanctum leaf extract was found to be an powerful genoprotectant. Furthermore works are to be carried out in future to find the extract mechanism of its genoprotective nature.
\end{abstract}

Keywords Antigenotoxic effect - Cyclophosphamide (CP) - Ocimum sanctum - Bio-synthesised silver nanoparticles $\cdot$ Chromosomal aberration assay $\cdot$ Human lymphocytes culture

P. P. Vijaya · B. Rekha · A. T. Mathew · M. Syed Ali $(\square)$. N. Yogananth $\cdot$ V. Anuradha $\cdot$ P. Kalitha Parveen

Department of Biotechnology, Mohamed Sathak College of Art and Science, Sholinganallur 600116, Tamil Nadu, India e-mail: syedmicro555@gmail.com

\section{Introduction}

Nanoparticle research is currently an area of intense scientific interest because of its wide range of applications in biomedical, optical and electronic fields. Nanomedicine which is one of the applications of nanotechnology uses nanomaterials which are introduced into human body to perform cellular repairs in the molecular level (Robert 2005). The main purpose of this paper is to evaluate the antigenotoxic effect of biologically synthesized silver nanoparticles against cyclophosphamide (CP). Осітиm sanctum which is an aromatic herb and shrub indigenous to tropical regions of Asia and America (Maimes Report: HolyBasil 2004). Tulsi is also known as "the elixir of life" since it promotes longevity (Govind Pandey and Madhuri 2010). Different parts of plant are used in Ayurveda and Siddha Systems of Medicine for prevention and cure of many ailments. It also possess significant properties like anti-inflammatory (Singh et al. 2007), immunomodulatory (Mediratta et al. 2002), anti-cancer (Aruna and Sivaramakrishnan 1992), antioxidant, analgesic, anti-anesthetic and chemo-preventive properties (Khanna and Bhatia 2003). A recent study reveals that Tulsi is a powerful COX-2 inhibitor because of its high content of eugenol and also shows protection against radiation poisoning. Some of the main chemical constituents of tulsi are-oleanolic acid, ursolic acid, rosmarinic acid, eugenol, carvacrol, linalool, $\beta$-elemene (has anti-cancer properties), $\beta$-caryophyllene and germacrene D (Mondal et al. 2009). Urosolic acid which is one of the constituents of tulsi is involved in reducing the free radical induced damage by various drugs (Uma Devi and Gonasoundari 2005).

Cyclophosphamide (CP) (Endoxan, Cytoxan, Neosar, Procytox, Revimmune) is one of the prodrug most widely used as anticancer-alkylating agent. It is bioactivated by

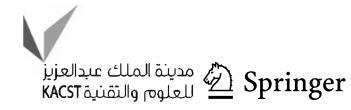


the liver CYP3 monooxygenase system for its therapeutic and toxic effects. It mainly used to treat cancer and various autoimmune disorders and also is a powerful carcinogen. $\mathrm{CP}$ prevents cell division primarily by cross linking DNA and RNA strands. Another serious side effect is low level of white blood cells or platelets and Infertility, in both men and women (which may be irreversible). Since the aqueous extract of tulsi has proved to be a powerful antigenotoxic agent (Dipanwita et al. 2007; Siddique et al. 2007). In this present study we made an attempt on antigenotoxicity effect from the silver nanoparticles of $O$. sanctum.

\section{Materials and methods}

Biosynthesis of silver nanoparticles

Fresh leaves and stem of $O$. sanctum were collected and cleaned. The collected samples were washed thrice with tap water and twice with distilled water. About $10 \mathrm{~g}$ of leaves and stems were taken and finely cut into small pieces and boiled with $100 \mathrm{ml}$ of double distilled water separately for $5 \mathrm{~min}$. The boiled extracts were filtered through Whatmann no. 1 filter paper. A total of $10 \mathrm{ml}$ of collected filtrate was treated with $90 \mathrm{ml}$ of $2 \mathrm{mM}$ silver nitrate aqueous solution and incubated at room temperature for $10 \mathrm{~min}$, resulting in the formation of brownish black colour indicating the synthesis of silver nanoparticles. After that, about $1 \mathrm{ml}$ (diluted with 1:20 V/V Milli $\mathrm{Q}$ water) of stems and leaves silver nanoparticle solution was monitored in UV-visible spectrophotometer (at $550 \mathrm{~nm}$ ) at different time intervals (15 min, $30 \mathrm{~min}, 4,6$ and $8 \mathrm{~h}$ ). After the incubation period, the solution was centrifuged at 12,000 rpm for $20 \mathrm{~min}$, and their pellets were re dispersed in Milli Q water. The centrifugation and redispersion was repeated three times to ensure the complete separation of nanoparticles (Gnanadesigan et al. 2012). Later the pellets were air dried. The air dried pellets of leaf extract was taken and mixed thoroughly with $2 \mathrm{ml}$ of DMSO stored at $4{ }^{\circ} \mathrm{C}$ for future use.

Human lymphocytes culture

Heparinized blood samples $(0.5 \mathrm{ml})$ was collected from healthy individuals and were placed in sterile culture flasks with $0.7 \mathrm{ml}$ of RPMI1640 supplemented with fetal bovine serum $(1.5 \mathrm{ml})$, antibiotic-antimycotic mixture $(1.0 \mathrm{ml})$, phyto haemagglutinin $(0.1 \mathrm{ml})$. The cultures are placed in incubator at $37^{\circ} \mathrm{C}$ for $24 \mathrm{~h}$.

Chromosomal aberration assay

After $24 \mathrm{~h}$ of incubation, the lymphocytes were treated with silver nanoparticles (SNPs) of O. sanctum leaf extract
(50, 100, $200 \mu \mathrm{l})$ with $\mathrm{CP} 100 \mu \mathrm{g} / \mathrm{ml}$ in separate culture tubes and placed in incubator at $37 \mathrm{C}$ for $48 \mathrm{~h}$. After $47 \mathrm{~h}$, $0.2 \mathrm{ml}$ of $0.01 \%$ colchicine was added to each vials and incubated at $37 \mathrm{C}$ for $45 \mathrm{~min}$. The cells were centrifuged at $1,000 \mathrm{rpm}$ for $5 \mathrm{~min}$ and the pellet was treated with $6 \mathrm{ml}$ of pre warmed $0.075 \mathrm{M} \mathrm{KCl}$ hypotonic solution and incubated at $37 \mathrm{C}$ for $15 \mathrm{~min}$. The supernatant was removed by centrifugation at $1,000 \mathrm{rpm}$ for $5 \mathrm{~min}$. The pellets are fixed by adding chilled fixative [methanol: acetic acid (3:1)]. The fixative was removed by centrifugation and this process is repeated twice. The slides were prepared and they were stained with $3 \%$ Giemsa stain solution in phosphate buffer (pH 6.8) for $15 \mathrm{~min}$. At least 300 metaphases were scored in each slide for examining different types of abnormality according to standard protocol of Savage (1979). Mitotic index (MI) was calculated by using formula,

$\mathrm{MI}=$ number of dividing cells/total number of cells $\times 100$

where MI, Mitotic index.

Characterization of silver nanoparticles

The optical absorbance of silver nanoparticles (of both leaf and stem extract) suspended in DMSO was recorded on UV-vis spectrophotometer in $200-800 \mathrm{~nm}$ wavelength range. The formation and quality of dried mixture of silver nanoparticles of $O$. sanctum leaf extract was checked by XRD technique (PAN analytical BV, The Netherlands) operated at a voltage of $40 \mathrm{kV}$, and a current of $30 \mathrm{~mA}$, with $\mathrm{CuKa}$ radiation in a h- $2 \mathrm{~h}$ configuration. Observation of the SNPs of $O$. sanctum leaf extract was done by Scanning Electron Microscopy (SEM).

Statistical analysis

The Mean and standard deviation was calculated for each parameter. The data was analyzed by 'SPSS 17.0' software. Two way ANOVA was performed to determine significance of treatment. The mean separation was performed according to Duncan's New multiple range test $(P \leq 0.05)$.

\section{Results}

The colour intensity of the bio-synthesised nanoparticles increase with time. On comparison between the SNPs of $O$. sanctum leaf and stem extract the leaf extract showed maximum Optical Density value (2.92) after $8 \mathrm{~h}$ of incubation (Fig. 1).

Table 1 shows the effect of SNPs of $O$. sanctum leaf extract on human lymphocyte culture (HLC) against CP. When human lymphocytes were treated with OS SNP leaf 


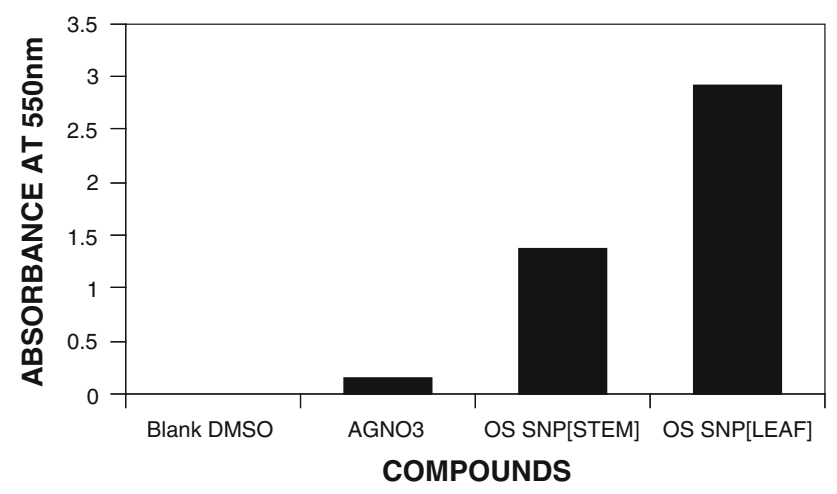

Fig. 1 UV-Vis analysis of silver nanoparticles from $O$. sanctum

mix alone at different doses of 50,100, and $200 \mu \mathrm{l} / \mathrm{ml}$, no increase in the number of chromosomal aberration and significant decrease in mitotic index were observed when compared with negative control. As SNPs of $O$. sanctum leaf extract at $1,000 \mu \mathrm{L} / \mathrm{mL}$ showed a reduction in Mitotic index (MI), further studies were carried out with lower doses on the basis of mitotic index as it is an indicator of cytotoxicity. Statistically there was significant reduction in the number of chromosomal aberration in different doses of SNPs of $O$. sanctum leaf extract. The protective effects of SNPs of $O$. sanctum leaf extract of which the concentration $200 \mu \mathrm{l} / \mathrm{ml}$ showed maximum protection against $\mathrm{CP}$ induced toxicity.

The FTIR spectrum of silver nanoparticles is shown in Fig. 2. The band at $3,400 \mathrm{~cm}^{-1}$ is assigned to the $\mathrm{O}-\mathrm{H}$ stretching of H-bonded alcohols and phenols. The band at $2,925 \mathrm{~cm}^{-1}$ is attributed to $\mathrm{O}-\mathrm{H}$ stretching of carboxylic acids. The band at $1,616 \mathrm{~cm}^{-1}$ corresponds to the $\mathrm{N}-\mathrm{H}$ bending of primary amines. The bands at 1,444 and
$1,521 \mathrm{~cm}^{-1}$ are related to the $\mathrm{C}-\mathrm{C}$ stretching of aromatic ring structure and the characteristic peak at $1,360 \mathrm{~cm}^{-1}$ corresponds to the $\mathrm{C}-\mathrm{N}$ stretching of aromatic amine group whereas in the region of $1,150-1,282 \mathrm{~cm}^{-1}$ are corresponding to the $\mathrm{C}-\mathrm{C}$ stretching alcohols, carboxylic acids, ethers and esters. From the FT-IR analysis, the presence of functional groups of alcohols, carboxylic acids, esters and ethers are binding metal with to form a silver nanoparticle is confirmed. These groups are also preventing the agglomeration of silver nanoparticles.

The morphology of the silver nanoparticles was determined by scanning electron microscopy. Figure 3 shows the SEM image of bio-synthesized silver nanoparticles. From the image it can be seen that the spherical morphology of silver nanoparticles is randomly distributed with average diameter $>100 \mathrm{~nm}$. The Energy Dispersive Analysis of X-rays (EDAX) spectrum revealed the presence of silver metal in synthesized nanomaterials. It is observed that the Ag nanoparticles are successfully synthesized (Fig. 4).

The X-ray Diffraction (XRD) pattern of silver nanoparticles is shown in Fig. 5. Three characteristic peaks of silver nanoparticles were observed at 38,44 and 64 which corresponds to the crystal face of (111), (200) and (220) of silver. The obtained data of silver metal was matched with the Joint Committee on Powder Diffraction Standards JCPDS No.89-3722. The grain size of the silver nanoparticles formed in the process was estimated from the Debye-Scherrer equation by determining the width of the (111), (200) and (220) Bragg's reflection. The average particle size is $50 \mathrm{~nm}$. It is observed that the silver nanoparticles are formed using $O$. sanctum leaf extract.

Table 1 Protective effect of silver nanoparticles (SNPs) of $O$. sanctum (OS) leaf extract against chromosomal aberrations induced by cyclophosphamide $(\mathrm{CP})$

\begin{tabular}{|c|c|c|c|c|c|c|c|}
\hline \multirow[t]{2}{*}{ Test substance } & \multirow[t]{2}{*}{ Mean \pm SD } & \multirow{2}{*}{$\begin{array}{l}\text { Mitotic } \\
\text { index }\end{array}$} & \multirow{2}{*}{$\begin{array}{l}\text { Number of } \\
\text { aberrated metaphase }\end{array}$} & \multicolumn{3}{|c|}{ Types of aberrations } & \multirow{2}{*}{$\begin{array}{l}\% \text { of } \\
\text { protection }\end{array}$} \\
\hline & & & & $\mathrm{B}$ & G & $\mathrm{P}$ & \\
\hline Untreated & $3 \pm 2$ & 6.2 & 3 & 3 & - & - & - \\
\hline DMSO $(0.1 \%)$ & $2.67 \pm 2.08$ & 4.5 & 2 & 1 & - & 1 & - \\
\hline $\mathrm{CP}(100 \mu \mathrm{g} / \mathrm{ml})$ & $33.33 \pm 3.51^{\mathrm{b}}$ & 1.7 & 33 & 23 & 8 & 2 & - \\
\hline OS SNP [LEAF] $(50 \mu \mathrm{l} / \mathrm{ml})$ & $2.67 \pm 2.08$ & 4.6 & 2 & 2 & - & - & - \\
\hline OS SNP [LEAF] $(100 \mu \mathrm{l} / \mathrm{ml})$ & $7.33 \pm 2.52$ & 4.5 & 7 & 4 & 1 & 2 & - \\
\hline OS SNP [LEAF] $(200 \mu \mathrm{l} / \mathrm{ml})$ & $8.67 \pm 2.52$ & 4.56 & 9 & 6 & 2 & 1 & - \\
\hline OS SNP [LEAF] $(50 \mu \mathrm{l} / \mathrm{ml})+\mathrm{CP}(100 \mu \mathrm{g} / \mathrm{ml})$ & $14.33 \pm 3.06^{\mathrm{a}}$ & 3.5 & 15 & 8 & 3 & 3 & 64.2 \\
\hline OS SNP [LEAF] $(100 \mu \mathrm{l} / \mathrm{ml})+\mathrm{CP}(100 \mu \mathrm{g} / \mathrm{ml})$ & $12.33 \pm 3.51^{\mathrm{a}}$ & 3.8 & 12 & 5 & 4 & 3 & 75 \\
\hline OS SNP [LEAF] $(200 \mu \mathrm{l} / \mathrm{ml})+\mathrm{CP}(100 \mu \mathrm{g} / \mathrm{ml})$ & $8 \pm 3^{\mathrm{a}}$ & 4 & 8 & 6 & 2 & - & 82 \\
\hline
\end{tabular}

$M I$ mitotic index, $B$ break, $G$ gap, $P$ pulverization, $S D$ standard deviation

NOTE- The results are average sets of five experiments (a, represents $P<0.005$, when compared to untreated and $\mathrm{b}$, represents $P<0.005$, when compared to $\mathrm{CP}$ ) 


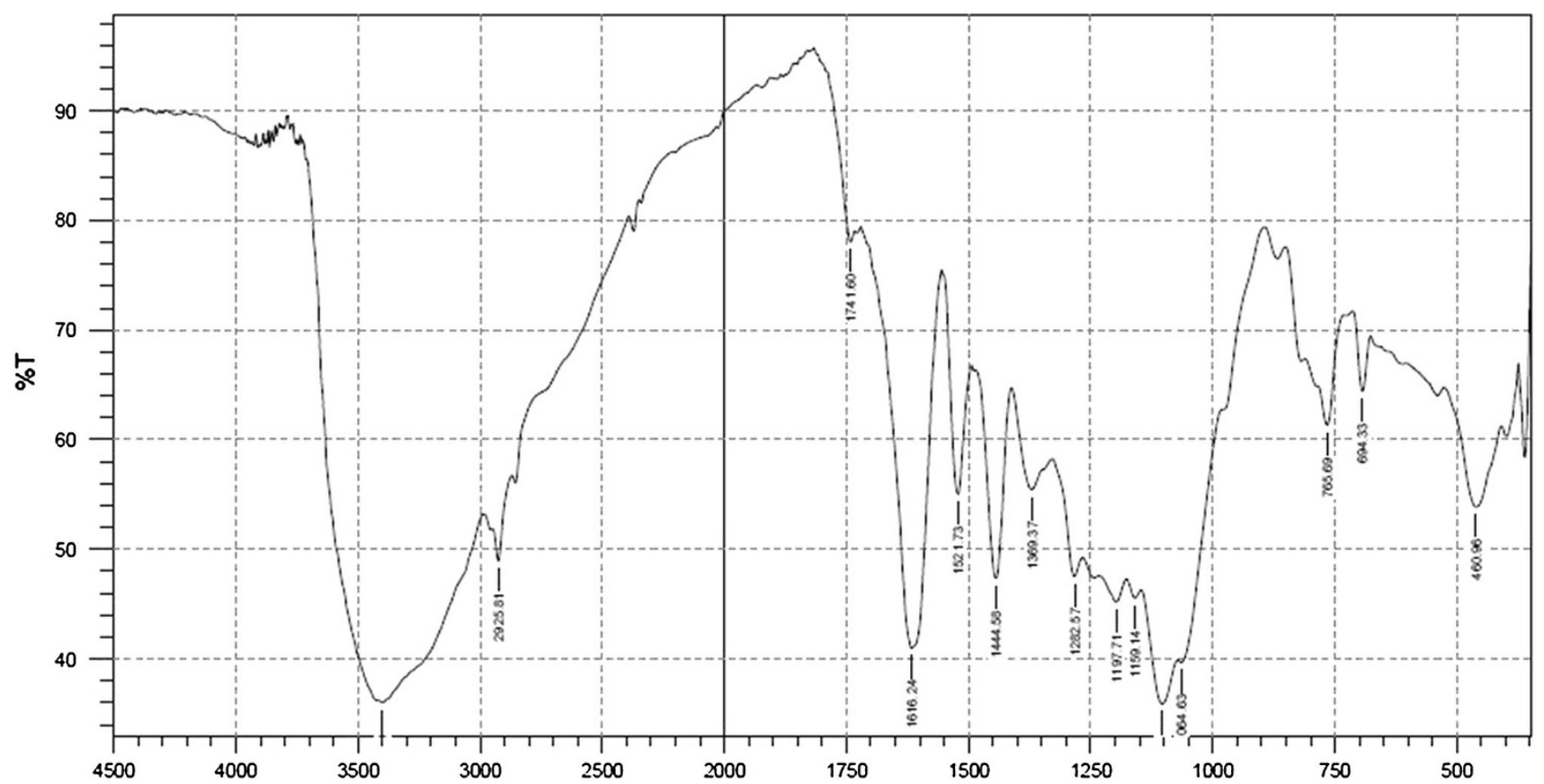

Fig. 2 FTIR spectrum analysis of bio-synthesised silver nanoparticles from $O$. sanctum leaf extract

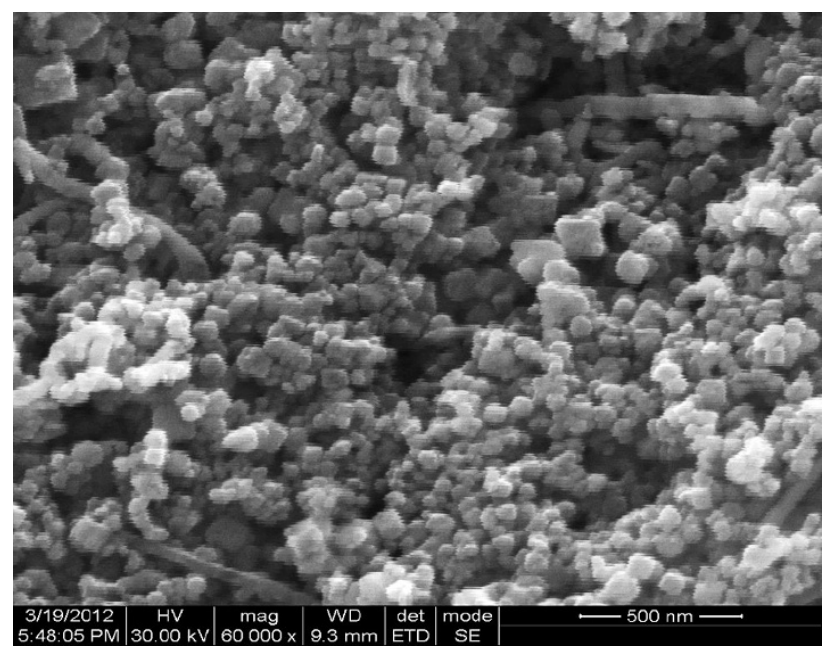

Fig. 3 Scanning electron microscopy image of bio-synthesized silver nanoparticles from $O$. sanctum leaf extract

\section{Discussion}

Nanomedicine can be broadly defined as a technology which uses molecular tools and knowledge about human body for medical diagnosis and treatment (Duncan 2004). Here the nanomaterial plays the pivotal therapeutic role because of their ability to cross biological barriers. Furthermore they can stimulate self-healing cell responses and bio compatibility of implants (Sato and Webster 2004). Moreover the developmental costs and risks of these c:ledax32 'genesisigenmaps.spc 19-Mar-2012 17:56:45 LSecs : 110

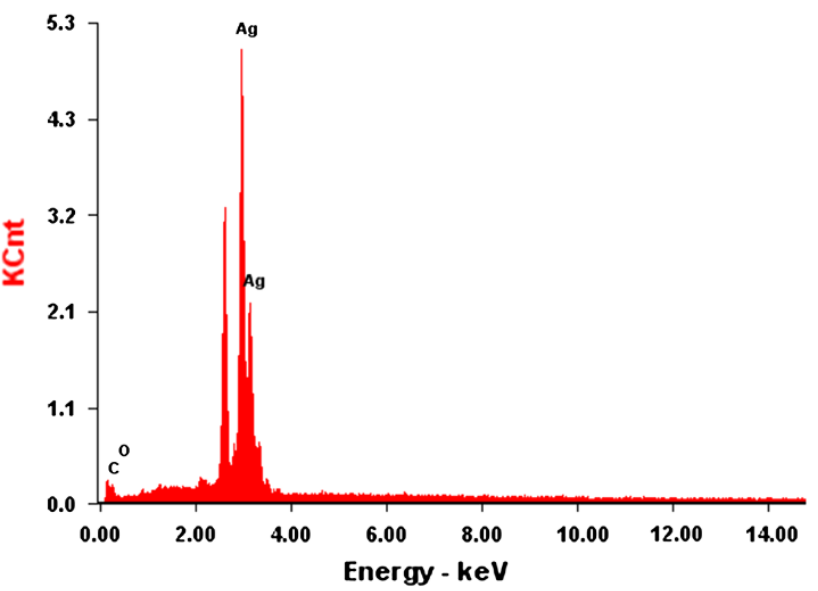

Fig. 4 EDAX spectrum revealed the presence of silver metal

materials are low as compared to other drugs. (Wagner et al. 2006).

Metal nanoparticles are well known for its applications in the field of electronics, magnetics and storing information. These properties are mainly because of their size, shape, composition and structure (Okuda et al. 2005). Of the metal Nps silver nanoparticles are well known for their catalytic properties (Toshima and Shiraishi 1999). The silver nanoparticles can be synthesised either chemically or biologically. The biological method is not only a good method but also effective in reducing the use or generation of hazardous compounds to the environment. Gold 


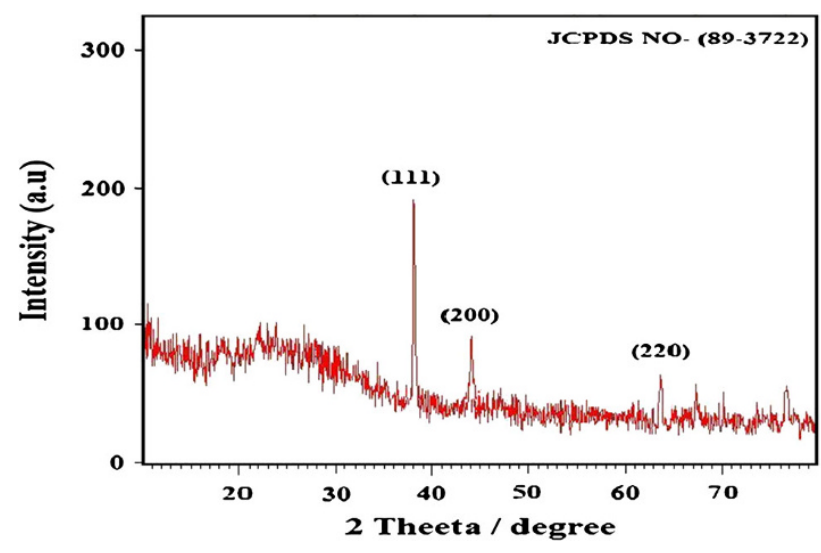

Fig. $5 \mathrm{XRD}$ analysis of bio-synthesised silver nanoparticles from $O$. sanctum leaf extract

nanotriangles were synthesised from Tamarind leaf extract and tested for its use as chemical sensors. Some plants like Alfalfa (Gardea-Torresdey et al. 2003) and neem (Shankar et al. 2004) were used in synthesis of silver Nps (SNP) in biological way.

Based on the view of all the above, the present study is mainly focussed on synthesis, characterisation and evaluating the antigenotoxicity of silver nanoparticles of $O$. sanctum. Previous studies revealed that synthesized Ocimum SNPs have potential anti-bacterial activity (Mallikarjuna et al. 2011; Singhal et al. 2011). On comparison with the stem, the leaf showed maximum synthesis because of their high phenolics, flavonoids (apigenin, luteolin) and tannins (Naheed et al. 2010). Further biosynthesis can be confirmed by appearance of brownish black colour upon addition of $\mathrm{AgNO}_{3}$ which is due to surface plasmon vibration of synthesised nanoparticles (Jayaseelan et al. 2010). The FTIR results of SNPs of $O$. sanctum leaf extract reveal the presence of $-\mathrm{C}-\mathrm{O}-\mathrm{C}-$ and $-\mathrm{C}=\mathrm{C}-$ functional groups and these groups are previously proved to have certain potential reducing agents in the synthesis of silver nanoparticles (Cho et al. 2005). The XRD pattern reveals sharp Bragg's peaks which are formed due to stabilisation of nanoparticles with the reducing agents in the $O$. sanctum leaves thus promoting crystallisation of the synthesized SNPs.

Plant infusions of $O$. sanctum $\left(1.075 \times 10^{-4}, 2.125\right.$ $\times 10^{-4}$ and $3.15 \times 10^{-4} \mathrm{gml}^{-1}$ ) have proved to reduce the genotoxic damage caused by chlormadinone acetate $(40 \mu \mathrm{M})$ by using parameters chromosomal aberration and sister chromatid exchange analysis (Siddique et al. 2008). In vivo cytogenetic assay which was carried out in Allium cepa root tip cells to detect the modifying effect of $O$. sanctum aqueous leaf extract against chromium $(\mathrm{Cr})$ and mercury $(\mathrm{Hg})$ induced genotoxicity (Babu and Uma Maheswari 2006). Antigenotoxic effects of Fullerenol $\mathrm{C} 60(\mathrm{OH}) 24$ nanoparticles $(\mathrm{FNP})$ were evaluated on human peripheral blood lymphocytes (PBL) using two cytogenetic assays namely-chromosomal aberrations (CA) and micronuclei (MN) tests on undamaged and mitomycin C(MMC) treated. Their results showed that FNP decreased chromosomal aberrations and micronucleus frequency on the undamaged and the MMC-damaged human PBL at concentration range from 5.54 to $221.60 \mu \mathrm{M}$ (Jasminka et al. 2012). Studies by Dipanwita et al. 2007 proved that $O$. sanctum leaf extract $(200 \mu \mathrm{g} / \mathrm{ml})$ which has active components like apigenin, luteolin, eugenol are responsible for their antigenotoxic ability. Siddique et al. 2008 tested the antigenotoxic effect of apigenin against chromosomal damage induced by cryptone acetate. Also $O$. sanctum leaf extract has proved to be a powerful genoprotectant against insecticides like chlorpyrifos (Khanna et al. 2011). In the similar way our present study on the protective effect of the SNPs of $O$. sanctum leaf extract against $\mathrm{CP}$ induced chromosomal aberration was found the highest at the maximum dose of $200 \mu \mathrm{l} / \mathrm{ml}$ showing $82 \%$ protection.

\section{Conclusion}

Nanomedicine is the phenomena which uses nanostructured or nanoscale products [size range up to $1,000 \mathrm{~nm}$ ] in medicine which have some unique medicinal properties based upon their structure. And the biological way of synthesising nanoparticles has potential applications like cost effectiveness, eco-friendly and compatibility for large scale production. In the present study the biosynthesis silver nanoparticles from $O$. sanctum leaf extract has proved to be a powerful antigenotoxicant. However our studies are preliminary and work has to be out in future to find the exact mechanism of genoprotectant activity of these biosynthesised silver nanoparticles.

Acknowledgments We are grateful thank to authorities of Mohamed Sathak College of Arts and Science and Mohamed Sathak Trust for providing facility and their encouragement to complete our work.

Open Access This article is distributed under the terms of the Creative Commons Attribution License which permits any use, distribution, and reproduction in any medium, provided the original author(s) and the source are credited.

\section{References}

Aruna K, Sivaramakrishnan VM (1992) Anticarcinogenic effects of some Indian plant products. Food Chem Toxicol 30:953-956

Babu K, Uma Maheswari KC (2006) In vivo studies on the effect of Ocimum sanctum L. leaf extract in modifying the genotoxicty induced by chromium and mercury in Allium root meristems. J Environ Biol 27(1):93-95 
Cho K, Park J, Osaka T, Park S (2005) The study of antimicrobial activity and preservative effects of nanosilver ingredient. Electrochim Acta 51:956-960

Dipanwita D, Saravanadevi S, Krishnamurthi K, Kumar K, Vyas P, Muthal PL, Naoghare PT, Chakrabarti P (2007) Modulatory effect of distillate of Ocimum sanctum leaf extract (tulsi) on human lymphocytes against genotoxicants. J Biomed Environ Sci 20:226-234

Duncan R (2004) Nanomedicines in action. Pharm J 273:485-488

Gardea-Torresdey J, Gomez LE, Peralta-Videa JR, Parsons JG, Troiani H, Yacaman MJ (2003) Natural source of the synthesis of silver nanoparticles. Langmuir 19:1357-1359

Gnanadesigan M, Anand M, Ravikumar S, Maruthupandy M, Syed Ali M, Vijayakumar V, Kumaraguru AK (2012) Antibacterial potential of biosynthesised silver nanoparticles using Avicennia marina mangrove plant. Appl Nanosci 2:143-147

Govind P, Madhuri S (2010) Pharmacological activities of Ocimum sanctum (tulsi): a review. Int J Pharma Sci Rev Res 5(1):61-66

Jasminka S, Slavica V, Aleksandar N, Gordana M (2012) Effects of fullerenol nano particles c60(oh) 24 on micronuclei and chromosomal aberrations' frequency in peripheral blood lymphocytes. Digest J Nanomat Biostruct 7(2):673-686

Jayaseelan C, Rahuman A, Rajakumar G, Kirthi A, Santhoshkumar V, Marimuthu T, Bagavan S, Kamaraj A, Zahir C, Elango G (2010) Synthesis of pediculocidal and larvicidal silver nanoparticles by leaf extract from heart leaf moon seed plant, Tinospora cordifolia Miers. Parasitol Res 107:585-592

Khanna N, Bhatia J (2003) Antinociceptive action of Ocimum sanctum (Tulsi) in mice: possible mechanisms involved. J Ethnopharma 88:293-296

Maimes Report: HolyBasil (2004) Ocimum sanctum-Tulsi version

Mallikarjuna K, Narasimha G, Dillip GR, Praveen B, Shreedhar B, Sree lakshmi C, Reddy BVS, Deva prasad Raju B (2011) Green synthesis of Silver nanoparticles using Ocimum leaf extract and their characterization. Digest J Nanomat Biostruct 6(1):181-186

Mediratta PK, Sharma KK, Singh S (2002) Evaluation of immunomodulatory potential of Ocimum sanctum seed oil and its possible mechanism of action. J Ethnopharma 80:15-20

Mondal S, Mirdha BR, Mahapatra SC (2009) The science behind sacredness of tulsi (Ocimum sanctum linn.). Ind J Physiol Pharmacol 53(4):291-306
Naheed A, Sharmab S, Alama K, Singh VN, Shamsid SF, Mehtac BR, Fatmae A (2010) Biosynthesis of silver nanoparticles from Desmodium triflorum: a novel approach towards weed utilization. J Biotech Res Int. doi:10.4061/2011/454090

Okuda M, Kobayashi Y, Suzuki K, Sonoda K, Kondoh T, Wagawa A, Kondo A, Yoshimura H (2005) Self-organized inorganic nanoparticle arrays on protein lattices. Nano Lett 5:991

Robert A (2005) Nanomedicine. Nanotech Bio Med 1(1):2-9

Sato M, Webster TJ (2004) Nanobiotechnology: implications for the future of nanotechnology in orthopedic applications. Expert Rev Med Devices 1:105-114

Savage JRK (1979) Classification and relationship of induced structural changes. J Med Gen 13:103-122

Shankar S, Rai A, Ahmad A, Sastry M (2004) Rapid synthesis of Au, $\mathrm{Ag}$, and bimetallic Au core-Ag shell nanoparticles using neem (Azadirachta indica) leaf broth. J Coll Int Sci 275(2):496-502

Siddique YH, Ara G, Beg T, Afzal M (2007) Anti-genotoxic effect of Ocimum sanctum extract against Cyproterone acetate induced genotoxic damage in cultured mammalian cells. Acta Biolog Hung 58(4):397-409

Siddique YH, Ara G, Beg T, Afzal M (2008) Possible modulating action of plant infusion of Ocimum sanctum L. on chromosomal aberrations and sister chromatid exchanges induced by chlormadinoneacetate in human lymphocytes in vitro. J Environ Biol 29(6):845-848

Singh S, Taneja M, Majumamdar DK (2007) Biological activities of Ocimum sanctum L fixed oil-an overview. Ind J Exp Bio 45:403-412

Singhal G, Bhavesh R, Kasariya K, Sharma AR, Singh RP (2011) Biosynthesis of silver nanoparticles using Ocimum sanctum (Tulsi) leaf extract and screening its antimicrobial activity. J Nanoparti Res 13(7):2981-2988

Toshima N, Shiraishi Y (1999). Synthesis and catalysis of polymerstabilized Ag and Ag/Pd. Colloids Sur Sci Cat 132:371-374

Uma Devi P, Gonasoundari A (2005) Radioprotective effect of leaf extract of Indian Medicinal Plant Ocimum sanctum. Ind J Exp Biol 33(1995):205

Wagner V, Dullaart A, Bock AK, Zweck A (2006) The emerging nanomedicine landscape. Nat Biotechnol 24:1211-1217 